the diseases known as nagana, surra, and caderas, by MM. A. Laveran and F. Mesnil. It has been previously shown that the nagana or disease of the tsetse fly and caderas, prevalent in South America, are distinct diseases, and a comparison of the Trypanosoma from the disease known as the surra with the two preceding shows that this is quite different from either. The three diseases are hence quite distinct.-The international congress of savants at the Universal Exhibition of St. Louis, 1904, by M. Newcomb. This congress will be held on September 19, 1904, and the five following days. A short account is given of its objects and the arrangements that have been made.-The drawings on the walls of the cave of Altamira (Spain), by MM. Emile cartailhac and the Abbé H. Rreuil. A comparison is made between these drawings and those recently described in the French caves. The style of work and colouring is similar in both, but in the Spanish cave the colouring is much superior to that in the French caves; it is noticeable that in the former drawings of the mammoth and reindeer are absent.-Remarks by M. Salomon Reinach on the preceding memoir. It is noteworthy that only animals which could be used for food are depicted in these caves, there being no representations of carnivora. The Aborigines of Central Australia also draw figures of animals on the rocks and soil, with the object of increasing their multiplication, and here, also, carnivora are naturally absent.-'The propagation of waves in elastic media, according as the media are conductors oi non-conductors of heat, by M. P. Duhem.-The perpetual secretary announced to the Academy the death of I. L. Cremona, correspondant for the section of geometry. -On surfaces which may, in several movements, give rise to a family of Lamé, by M. A. Demoulin.--On the simultaneous employment of the laws of distinct survival, by II. Albert Quiquet.-On a method of measuring the variation of the current in the armature in short circuit during the time of commutation in a continuous current dynamo, by $M$. Iliovici.--On the physical constitution of the atmosphere, by M. Louis Maillard. The usual formula for the density $\rho=273 / 760 p / T$ does not appear to hold when $p$ and 'T are both very small. From the author's calculations, which are partly based on results from captive balloons and partly on laboratory experiments, the density of the ai: diminishes up to a height of 30 to 50 kilometres, and then increases up to 75 kilometres $(\rho=0 \cdot 21)$. If these results are correct, the theories of astronomical refraction will require some modifications.--On the estimation of vanadium in alloys, by $M$. Paul Nicolardot. The method of Sefström (the solution of the alloy in sulphuric or hydrochloric acid) for the qualitative detection of vanadium in Swedish iron, when slightly modified, can be made quantitative. Comparative analyses of the same sample by three methods are given.-On the esterification of the hydracids, by M. A. Villiers.-On the benzoyl derivatives of hydrazobenzene, by M. P. Freundler.-On the action of abietic acid on ferments, by M. Jean Effront.-On some combinations of chloride of gold and pyridine, by M. Maurice François.-The phenyl substitution in the phenylmethanes, their carbinols and chlorides, by M. Jules schmidlin. A thermochemical paper.--The preparation of alkyl nitrates and nitrites, by MM. L. Bouveault and A. Wahı. Excellent yield of nitric esters can be obtained by the use of anhydrous nitric acid in the case of the primary alcohols; with secondary alcohols the action is quite different, the corresponding ketone being the main product of the reaction; with tertiary alcohols the action is destructive. The action of pure $\mathrm{HNO}_{3}$ is suggested as a reagent for differentiating between the three classes of alcohols. Excellent yields of nitrous esters were obtained by the action of nitrosyl chloride upon a mixture of the alcohol and pyridine at $o^{\circ}$ C.-Chlorine derivatives of methylene chloroacetate and diacetate, by M. Marcel Descud6.-On some new members of the pyranic series, by MM. R. Fosse and A. Robyn.--On stachyose, by M. C. Tanret. It is shown that manneotetrose and stachyose are identical, the composition being $\mathrm{C}_{24} \mathrm{H}_{42} \mathrm{O}_{21}$.-Comparisons between the phenomena of nutrition in seedlings with or without their cotyledons, by M. G. André.-On some conditions of oxidation of salicylic aldehyde by organs and extracts of organs, by MM. J.-E. Abelous and J. Aloy. The oxidation of salicylic aldehyde in extracts from the liver of the horse or calf goes on better in a vacuum than in air, the presence of free oxygen diminishing, or even suppressing, the oxidation.-On the glycerol in the blood, by $M$. Maurice Nicloux.-On mixtures of iodine and sulphur, by M. R. Boulouch. From a dilatometric study it would appear that sulphur and iodine when fused together give rise to neither definite compounds nor solid solutions.-The action of the magnetic field on the infusoria, by MM. C. Cheneveau and G. Bohn. Contrary to the results obtained by M. H. du Bois, it is found that an intense magnetic field modifies the ciliary movements, the growth, and the multiplication of the infusoria.-The law of the action of trypsin on gelatin, by MM. Victor Henri and I arguier des Bancels. - The family of the Clostridiacex, by M. Paul Vuillemin.-On the structure of the seed of Vymphaea flava, by M. J. chimot. -The disease of the plane tree, by $M$. J. Beauverie.-On the exotic plant species in the immediate neighbourhood of Béziers (Hérault), by M. P. Carles.-On the geology of the Oubangui district at Tchad, by M. Lacoin.--The poisons of the organism and gestation, by MM. Charrin and Roche..-The results of phototherapy and the technique of its application in lupus, by M. Finsen. Statistics of the results obtained in the treatment of lupus at the Finsen Institute, Copenhagen, with some details of the mode of treatment.

\section{DIARY OF SOCIETIES}

\section{FRIDAY. JUI.Y 3 .}

Institution of Mining Engineers, at xr.30 a.m.--Further Remarks on the Portuguese Manica Gold-field: A. R. Sawyer-Coal fields of the Faröe Islands: E. A. Greener.-Miners' Anamia or Ankylostomiasis : Dr. J S. Haldane, - Water-softening Plant: Vincent Corbett.-The Redevelopment of the Slate-trade in Ireland: O. H. Kinahan.-The Smelters of British Columbia: W. Denham Verschoyle.-The Commonsense Doctrine of Furnace-draught: H. W. Halbaum.-The Ventilation of Deep Mines : Arthur C. Murray.

Grologists' Association, at 8.- Some Flint Implements from Reading and Maidenbead: Ll. Treacher.

\section{CONTENTS.}

The Biography of Helmholtz. By Sir J. Burdon-

Sanderson, Bart., F.R.S., and Harold Hilton The Earth-history of Central Europe. By T. G. B. 196 Our Book Shelf :-

Whetham: "A Treatise on the Theory of Solution, including the Phenomena of Electrolysis"

Brough: "The Study of Mental Science."-W $\mathrm{MCD}$.

Hasluck: "Photography"; Kilbey: "Hand Camera Photography"

Colomer: "Mise en Valeur des Gîtes Minéraux". . 198 Letters to the Editor:-

Psychophysical Interaction.-Prof. J. H. Muirhead 198 Tables of Four-figure Logarithms. - Prof. John Perry, F.R.S.

Ship's Magnetism. - Capt. E.W. Creak, C. B.,F.R.S. 199

Mercury Bubbles.-Dr. Henry H. Dixon . . . . . 199

Radium Flucrescence. $-F$. Harrison Glew 200

A New Series in the Magnesium Spectrum. - William Sutherland

The Kite Competition of the Aëronautical Society 200 The Celtic Gold Ornaments . . . . 201 The University of London . . . . . . . . . . 201 A Charlotten burg Institute for London . . . . 203 The British Academy . . . . . . . . . . . 204 Notes . . . . . . . . . . . 205 Our Astronomical Column:-

Reported Change on Saturn . . . . . . . . . . 207

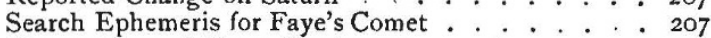

Observations of Nova Geminorum . . . . . . . 207

The Red Spot on Jupiter . . . . . . . . . 208

The Study of very Faint Spectra . . . . . . . . . 208 Institution of Naval Architects . 208 The International Congress for Applied Chemistry. By Dr. H. Borns South-eastern Union of Scientific Societies . . 209 University and Educational Intelligence . . . . 2 II Societies and Academies . . . . . . . . . . . . . 212 Diary of Societies . . . . . . . . . . 216 NO. I 757 , vOL. 68] 